\title{
«ES DE CAJÓN, SEÑORÍAS»: LOCUCIONES, ANALOGÍAS Y OTRAS EXPRESIONES EN LA OPOSICIÓN DE RAJOY (2005-2011)
}

\author{
Beatriz Figueredo Flores \\ Grupo Ilse / CySOC
}

\section{INTRODUCCIÓN}

El carácter polémico del discurso parlamentario determina la presencia de múltiples y variadas expresiones lingüísticas de carácter idiomático que desempeñan un papel determinante cuando se trata de dañar la imagen del oponente. Entre ellas se encuentran las locuciones, paremias y otros giros que dotan al texto de un marcado carácter expresivo.

$\mathrm{Su}$ pertenencia al acervo popular, su contenido denotativo y la función didáctica perseguida con su empleo, entre otras cualidades, los convierten en un recurso nada desdeñable para hacer de los argumentos en los que el opositor fundamenta su exposición un potente instrumento persuasivo que asegure una directa y eficaz llegada al interlocutor. En este artículo presentamos una clasificación de tales manifestaciones en los discursos iniciales de Mariano Rajoy como líder de la oposición en los debates en torno al estado de la nación celebrados en España entre 2005 y 2011.

\section{UNIDADES FRASEOLÓGICAS Y OTRAS PARTICULARIDADES LÉXICO-RETÓRICAS EN LAS RÉPLICAS DE RAJOY}

\subsection{Unidades fraseológicas}

Han sido variadas las nominaciones que ha recibido el objeto de estudio de la fraseología, entre ellas expresiones fijas (Zuloaga 1980), locuciones (Ruiz Gurillo 1997), modismos (Casares 1950), expresiones idiomáticas (Sevilla y Arroyo 1993), fraseologismos (Martí Sánchez 1999) y unidades fraseológicas ${ }^{1}$

\footnotetext{
${ }^{1}$ En estos términos las define la autora: «Unidades léxicas formadas por más de dos palabras graficas en su límite inferior, cuyo límite superior se sitúa en el nivel de la oración com- 
(Zuloaga 1980; Corpas 1997). Por nuestra parte, tomaremos como referencia la última de ellas por parecernos más apropiada para hacer referencia a estos elementos; asimismo, seguiremos la clasificación que de ellos ofrece Corpas, en correspondencia con la cual ordenaremos los resultados de nuestro estudio. Por otro lado, habida cuenta de la ausencia de colocaciones ${ }^{2}$ entre las unidades destacadas de nuestro corpus, partiremos en primera instancia de los elementos que la autora sitúa en la esfera $\mathrm{II}^{3}$, esto es, las locuciones presentes en las réplicas del líder de la oposición popular, y así mismo prescindiremos de las fórmulas rutinarias incluidas en los enunciados fraseológicos.

\subsubsection{Locuciones}

Se trata del elemento que se encuentra con una mayor profusión entre las unidades fraseológicas empleadas por Rajoy, pues de un total de 32 unidades de este tipo, las locuciones rastreadas en sus réplicas son 26. Para su clasificación hemos tomado en cuenta los criterios que exponemos seguidamente. En primer lugar, las hemos agrupado según la finalidad perseguida mediante su enunciación. Como dijimos en la introducción, teniendo en cuenta el carácter eminentemente polémico de este tipo de discurso y el papel de ataque al poder asumido por la oposición, no es de extrañar que casi su totalidad constituya una manifiesta agresión a la imagen del

puesta. Dichas unidades se caracterizan por su alta frecuencia de uso, y de coaparición de sus elementos integrantes; por su institucionalización, entendida en términos de fijación y especialización semántica; por su idiomaticidad y variación potenciales; así como por el grado en el cual se dan todos estos aspectos en los distintos tipos» (Corpas Pastor 1997: 20-24).

${ }^{2}$ Recordemos que, a diferencia de las locuciones, las colocaciones presentan un claro grado de relación semántica entre sus componentes, con el consecuente significado literal de sus componentes («trasplantar un órgano», «tocar la guitarra»). Además, debido a su menor grado de fijación, admiten variaciones gramaticales («luchar encarnizadamente» por «lucha encarnizada»).

${ }^{3}$ Para Corpas, las unidades fraseológicas se agrupan en torno a tres esferas que se corresponden con los tres niveles de la lengua: norma, sistema y habla. De este modo, según su inscripción en cada uno de estos planos, hablaremos de colocaciones, locuciones o enunciados fraseológicos, respectivamente.

TABLA 1. División de las unidades fraseológicas según Corpas (1997)

\begin{tabular}{l|c|c|c}
\hline \multicolumn{1}{l}{ Esfera } & \multicolumn{2}{c}{ I } & II \\
\hline Denominación & Colocaciones & Locuciones & Enunciados fraseológicos \\
\hline Equivalencia sintáctica & \multicolumn{2}{|c|}{ Sintagmas } & Enunciados completos \\
\hline Nivel de fijación & Norma & Sistema & Habla \\
\hline
\end{tabular}


interlocutor. Sin embargo, esto no obsta para que también se dedique un número -aunque notoriamente más modesto- a realzar la autoimagen.

Asimismo, estas dos variantes primarias presentan un número determinado de subestrategias que hemos caracterizado partiendo de dos factores diferentes. Mientras las locuciones encaminadas a dañar la imagen del contrincante constituyen un continuum determinado por el grado de implicación de tal amenaza, las que implican el autorrealce son formuladas mediante contrastes en los que se pretende dejar patente la ineptitud del interlocutor frente a la eficacia lograda con la gestión del gobierno ejercido bajo el mando de su grupo político (cfr. Tabla 3).

\subsubsection{De ataque a la imagen positiva del adversario}

Todos los mecanismos contenidos en este primer nivel divisorio cumplen el objetivo de mostrar la inconveniencia de la continuación en el poder del presidente mediante la crítica de sus acciones. En virtud de su alcance, estas se pueden desglosar en otros tres órdenes: si la focalización de tal disención se sitúa en el mismo Rodríguez Zapatero, Presidente del Gobierno durante aquellos años, el ataque será directo. Ahora bien, si el ataque incluye al mismo tiempo a los miembros del grupo contrario, lo consideramos de nivel intermedio. El grado indirecto, por su parte, contiene una mayor

FIGURA 1. Grados del ataque a la imagen en Rajoy según su implicación

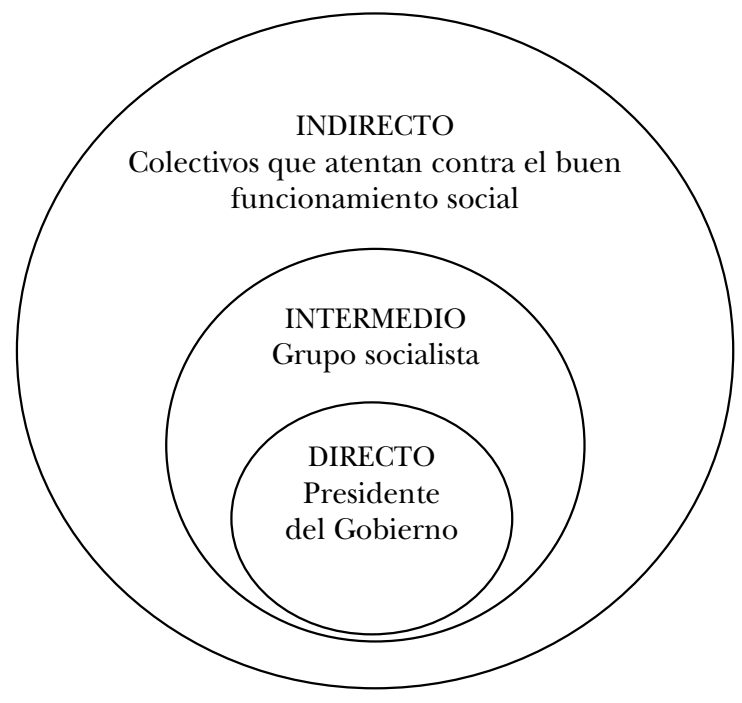


implicación en tanto su extensión involucra además a agentes externos a los anteriormente mencionados, a los que se atribuyen acciones reprobables de intensidad variable que oscilan entre las de menor implicación social (ejemplos 14 y 15) y las más extremas (ejemplos 16 y 17).

\subsubsection{Directo}

El líder de la oposición popular emplea en este caso un número considerable de locuciones mediante las cuales pretende destacar la falta de idoneidad de Rodríguez Zapatero como gobernante. Por este motivo tales acusaciones harán alusión a aspectos tan variados como su propia actitud (ejemplos 1 y 2 ), errores cometidos y sus consecuencias $(9,10,11)$ y falta de credibilidad (ejemplo 12), de todo lo cual se deduce una lógica incompetencia (ejemplos 3-8). Precisamente, la gravedad de tales imputaciones radica en la explícita vinculación de estos actos de habla con la figura del oponente.

Seguidamente presentamos el elenco de expresiones locutivas de ataque directo emitidas por Rajoy. Aunque la mayoría está constituida por un solo enunciado, algunas de ellas contienen dos, como es el caso de los ejemplos 3, 12 y 19, en los que el ataque aparece reforzado mediante la unión de estos dos elementos a través del nexo conjuntivo y en el primer caso, el disyuntivo $o$ en el segundo y el adversativo pero en el último. Mediante esta presentación binaria el portavoz logra una intensificación del efecto contenido en su enunciación, lo que se corresponde con el consecuente impacto en el interlocutor.

a) Agarrarse a un clavo ardiendo

(1) Nos dice, como quien se agarra a un clavo ardiendo, que se trata de una tarea inaplazable cuya interrupción no acarrearía más que prejuicios (Rajoy 2011)

b) A la chita callando

(2) Habla poco, como quien no se atreve a confesar sus intenciones, lleva sus cosas a la chita callando [...] (Rajoy 2005)

c) A trompicones/a matacaballo

(3) Si lo hizo mal cuando no tenía prisas ¿cómo lo hará ahora que responde a trompicones y a matacaballo? (Rajoy 2010)

d) Al alimón

(4) ¿Cuántos ministerios llevan al alimón este problema [...]? (Rajoy 2006) 
e) Escurrir el bulto

(5) Todos esos son latiguillos a los que recurre insistentemente para evitar responder y escurrir el bulto (Rajoy 2010)

f) Meter la cabeza debajo del ala

(6) A propósito, señor Rodríguez Zapatero: hablando de política exterior y de defensa, ¿qué sentido tiene que meta usted la cabeza debajo del ala [...]? (Rajoy 2007)

g) Irse por las ramas

(7) ... lo suyo es disfrazar la verdad e irse por las ramas... (Rajoy 2007)

h) Poner una pica en Flandes

(8) Su política de educación [...] ha puesto una pica en Flandes (Rajoy 2005)

i) Sembrar cizaña

(9) Eso que llaman Ley de Memoria Histórica [...] no tiene más efecto práctico que sembrar cizaña entre los españoles (Rajoy 2007)

j) Volver a las andadas

(10) Mas aún, está en juego si podrá usted o no volver a las andadas (Rajoy 2007)

k) Lo que no está en los escritos

(11) Las restricciones crediticias [...] son más severas en España que en los demás países de la unión monetaria, porque debemos lo que no está en los escritos [...]

1) Arrimar el hombro/remar juntos

(12) Señorías, a estas alturas ni siquiera convencen a nadie las alegorías de arrimar el hombro o remar juntos (Rajoy 2010)

\subsection{Intermedio}

Contrasta con la profusión anterior la restricción a un único registro con generalización de las críticas al grupo socialista, al que hace extensiva la gravedad de sus reproches:

a) Vender aire

(13) Se mueven mucho, pero no venden más que aire (Rajoy 2005) 


\subsection{Indirecto}

Los siguientes enunciados contienen reproches que el líder conservador dirige a Rodríguez Zapatero por su vinculación con agentes externos al Gobierno que o bien presentan una conducta reprobable (ejemplo 14) o actúan movidos por propósitos poco convenientes para la nación (ejemplo 15). En otra instancia se encuentran las menciones al incremento de la actividad delictiva con la llegada de bandas internacionales (ejemplo 16) y el resurgimiento del conflicto terrorista de ETA (ejemplo 17) como resultado de la acción del presidente socialista.

a) Bailar el agua

(14) Durante todo este año no han atendido más que a dos tipos de personas: los que le bailan el agua y los que le chantajean (Rajoy 2005)

b) Chupar del bote

(15) No es Cataluña, señor presidente [...], sino algunos correligionarios o aliados suyos, los que intentan evitar que la ciudad de Madrid consiga los juegos olímpicos de 2012 [...] o los que chupan del bote (Rajoy 2005)

c) Colarse de rondón

(16) Hay más, nos estamos enfrentando a unos tipos de delincuencia que no conocíamos, una delincuencia importada [...] que se nos ha colado de rondón entre nosotros sin que nada ni nadie se lo impida (Rajoy 2006)

d) Con la rodilla en tierra

(17) ... vamos a luchar contra una ETA crecida, envalentonada, reconstruida por su culpa [...], que ha fortalecido su esperanza de vernos un día con la rodilla en tierra (Rajoy 2007)

\subsubsection{De refuerzo de la autoimagen}

El rol institucional de candidato opositor ejercido por Rajoy, que predispone a la crítica y el ataque, no obsta para que dedique también a la audiencia un par de muestras de la valía de la opción que representa su partido. Tal estrategia es ejecutada mediante el establecimiento de acciones que manifiestan una clara disparidad de valores a favor del interesado (ejemplo 19) o que destacan los frutos de un trabajo bien hecho en el pasado (ejemplo 18). 


\subsection{Enfatizando logros}

a) Apretar el cinturón

(18) Usted no encontró un país arruinado, no ha tenido que apretar el cinturón a los españoles para que pudiéramos entrar en el euro a la primera [...] (Rajoy 2006)

\subsection{Rechazando conducta}

\section{b) Hacer leña del árbol caído/correr cortina}

(19) No pretendo hacer leña del árbol caído, señorías, pero tampoco voy a correr una cortina que nos oculte la realidad nacional [...] (Rajoy 2007)

TABLA 2. Clasificación funcional de las locuciones en la oposición de Rajoy

\begin{tabular}{|c|c|c|c|c|c|c|c|}
\hline \multicolumn{6}{|c|}{ ATAQUE IMAGEN DEL ADVERSARIO } & \multirow{2}{*}{\multicolumn{2}{|c|}{$\begin{array}{c}\text { REFUERZO } \\
\text { IMAGEN PROPIA } \\
\text { MEDIANTE } \\
\text { CONTRASTES }\end{array}$}} \\
\hline \multicolumn{4}{|c|}{$\begin{array}{c}\text { DIRECTO } \\
\text { (centrado en su persona) }\end{array}$} & \multirow[b]{2}{*}{$\begin{array}{c}\text { INTERMEDIO } \\
\text { (en su } \\
\text { grupo) }\end{array}$} & \multirow{2}{*}{$\begin{array}{l}\text { INDIRECTO } \\
\text { (tomando } \\
\text { como } \\
\text { referencia } \\
\text { hechos, } \\
\text { entidades } \\
\text { o grupos } \\
\text { ajenos) }\end{array}$} & & \\
\hline Actitud & Incompetencia & Errores & $\begin{array}{c}\text { Falta de } \\
\text { credibilidad }\end{array}$ & & & $\begin{array}{c}\text { Destacando } \\
\text { los logros }\end{array}$ & $\begin{array}{l}\text { Rechazando } \\
\text { su conducta }\end{array}$ \\
\hline $\begin{array}{l}\text { Agarrarse } \\
\text { a un } \\
\text { clavo } \\
\text { ardiendo }\end{array}$ & $\begin{array}{l}\text { Irse } \\
\text { por las } \\
\text { ramas }\end{array}$ & $\begin{array}{l}\text { Poner } \\
\text { una pica } \\
\text { en } \\
\text { Flandes }\end{array}$ & $\begin{array}{l}\text { Arrimar } \\
\text { el hombro }\end{array}$ & Vender aire & $\begin{array}{l}\text { Bailar } \\
\text { el agua }\end{array}$ & $\begin{array}{l}\text { Apretarse } \\
\text { el cinturón }\end{array}$ & $\begin{array}{l}\text { No hacer } \\
\text { leña } \\
\text { del árbol } \\
\text { caído }\end{array}$ \\
\hline $\begin{array}{l}\text { A la chita } \\
\text { callando }\end{array}$ & $\begin{array}{c}\text { A } \\
\text { trompicones }\end{array}$ & $\begin{array}{l}\text { Sembrar } \\
\text { cizaña }\end{array}$ & $\begin{array}{l}\text { Remar } \\
\text { juntos }\end{array}$ & $x$ & $\begin{array}{l}\text { Chupar } \\
\text { del bote }\end{array}$ & $x$ & $\begin{array}{l}\text { Correr } \\
\text { cortina }\end{array}$ \\
\hline$x$ & $\begin{array}{c}\mathrm{A} \\
\text { matacaballo }\end{array}$ & $\begin{array}{c}\text { Volver } \\
\text { a las } \\
\text { andadas }\end{array}$ & $x$ & $x$ & $\begin{array}{c}\text { Colarse } \\
\text { de rondón }\end{array}$ & $x$ & $x$ \\
\hline$x$ & Al alimón & $\begin{array}{l}\text { Lo que } \\
\text { no está } \\
\text { en los } \\
\text { escritos }\end{array}$ & $x$ & $x$ & $\begin{array}{l}\text { Con } \\
\text { la rodilla } \\
\text { en tierra }\end{array}$ & $x$ & $x$ \\
\hline$x$ & $\begin{array}{l}\text { Escurrir } \\
\text { el bulto }\end{array}$ & $x$ & $x$ & $x$ & $x$ & $x$ & $x$ \\
\hline
\end{tabular}




\subsubsection{Enunciados fraseológicos: Paremias}

Siguiendo a Corpas (1997), dentro de la esfera III se encuentran los enunciados fraseológicos, que incluyen las paremias y las fórmulas rutinarias (cfr. Tabla 1). Si estas últimas no constituyen un dato de interés para el presente estudio, no ocurre lo mismo con las primeras, manifiestas en forma de citas, refranes y paremias con valor específico, como veremos a continuación.

Si bien en muchos casos es difícil distinguir la paremia (sinónimo de refrán, proverbio, adagio y sentencia, cfr. DRAE 2001) de la fórmula rutinaria, según Corpas es posible rastrear la presencia de dos puntos de divergencia entre ambas: su función y su nivel de autonomía textual (cfr. Tabla 3).

TABLA 3. Diferencias entre paremias y fórmulas rutinarias según Corpas (1997: 272-275)

\begin{tabular}{ccc}
\cline { 2 - 3 } & PAREMIAS & FóRMULAS RUTINARIAS \\
\hline SIGNIFICADO & Referencial & Social, expresivo o discursivo \\
\hline $\begin{array}{c}\text { NIVEL DE AUTONOMÍA } \\
\text { TEXTUAL }\end{array}$ & Máximo & Sujeto a circunstancias concretas \\
\hline FUNCIÓN & $\begin{array}{c}\text { Fática } \\
\text { (persuadir })\end{array}$ & Facilitar la interacción \\
\hline
\end{tabular}

Igualmente, hay ocasiones en las que la distinción de estas unidades de las locuciones resulta muy difícil debido al hecho de que muchas de estas han sido originadas a partir de una paremia (Corpas 1997: 132-134). En este sentido también la autora presenta tres criterios que deben tomarse en cuenta para su identificación: su carácter, pertenencia y la posibilidad o no de permitir variaciones sintácticas (cfr. Tabla 4). No obstante, Ruiz Gurillo plantea una solución más sintética al reducir los criterios de diferenciación entre ambas a uno: su grado de autonomía ${ }^{4}$, presente en las locuciones y ausente en las paremias (Ruiz Gurillo 2000: 178). Este ha sido el principio que hemos tomado como referencia en la tipificación de las unidades halladas en nuestro corpus cuya consideración como una u otra se presentara a priori dudosa por su ambigüedad.

\footnotetext{
${ }^{4}$ Propiedad ya señalada por Corpas ( $c f r$. nota anterior).
} 
TABLA 4. Diferencias entre paremias y locuciones según Corpas (1997: 134-135)

\begin{tabular}{ccc}
\cline { 2 - 3 } & Paremias & LOCUCIONES \\
\hline CARÁCter & General & Específico \\
\hline CAMbios & Permitidos (salvo concordancias) & Permitidos en cierto grado \\
\hline PERTENENCIA & Unidades de habla & Sistema de la lengua \\
\hline
\end{tabular}

\subsubsection{De valor específico}

a) Piove, porco Governo

(20) No responsabilizo ni culpo al Gobierno de todos los males o todas las tragedias, no soy de los que piensa piove, porco Governo y, si no llueve, también porco Governo. No me lo permiten ni mi experiencia en la vida pública ni mi talante, porque yo, humildemente, también tengo mi talante, señorías (Rajoy 2005)

b) Vivir de las rentas

(21) En la economía, por decirlo pronto, vive usted de las rentas, de la historia recibida y de las rentas que esta genera (Rajoy 2005)

c) Es de cajón

(22) Decidió por su cuenta replantear el modelo territorial sin molestarse en hacer -si es que es de cajón- un diagnóstico previo [...] (Rajoy 2007)

(23) Las restricciones crediticias [...] son más severas en España que en los demás países de la unión monetaria, porque debemos lo que no está en los escritos y la caída de la confianza en las empresas y en las familias es mucho más intensa que en el resto de la Unión Europea. Es de cajón, señorías (Rajoy 2009)

\subsubsection{Citas}

(24) Como decía Ortega, el verdadero tesoro del hombre es el tesoro de sus errores (Rajoy 2007)

\subsubsection{Refranes}

Dos son los únicos registros del refranero español que hemos encontrado en el corpus: 
e) Mal de muchos, consuelo de tontos

(25) Y no vale, señorías, escudarse en la crisis internacional aplicando el viejo refrán: mal de muchos, consuelo de tontos [...] (Rajoy 2011)

\section{f) Para ese viaje no se necesitan alforjas}

(26) Si dijéramos mañana a los españoles que, tras un sesudo debate de dos días, hemos concluido que estamos [...] peor que hace un año, lo más suave que podríamos escuchar es que para ese viaje no se necesitan alforjas (Rajoy 2011)

\subsection{Referencias}

Entendemos por referencia la mención, explícita o indirecta, de un enunciado de extensión variable que remite a una fuente perteneciente al acervo cultural compartido por el emisor y receptor/es de su comunicación. Se trata de otro recurso de gran interés para el orador político por su carácter bivalente, pues del mismo modo que puede ser empleado como instrumento de alabanza, el efecto conseguido puede ser el contrario, esto es, la ofensa. Precisamente esta última opción es la que condujo al candidato popular a mencionar las cuatro alusiones totales que pudimos constatar en nuestro corpus, pues todas ellas están encaminadas a dejar en entredicho la capacidad del presidente para ejercer su labor gubernamental. Las cuatro referencias mencionadas de Rajoy son de tres tipos: literarias, bíblicas e históricas.

\subsubsection{Literarias}

Dos son las referencias literarias presentes en las intervenciones de Rajoy, ambas pertenecientes a nuestra moderna tradición literaria: El Quijote (ejemplo 27) y uno de los artículos de Mariano José de Larra, «Vuelva usted mañana» (ejemplo 28). La primera de ellas fue pronunciada en su réplica de 2007. En ella se menciona la conocida expresión «bálsamo de Fierabrás», empleada como jocoso sinónimo de «panacea universal» capaz de acabar con todo mal $^{5}$ (ejemplo 27). De otro lado, la alusión larriana pertenece al

${ }^{5}$ Aunque fue popularizada por Cervantes en su inmortal obra (Capítulo X, volumen I), este concepto se remonta a la tradición legendaria del ciclo épico carolingio (siglo XII), según la cual cuando el emir Balán y su hijo Fierabrás de Alejandría conquistaron Roma, robaron los restos del bálsamo atribuido al embalsamamiento de Jesucristo; de ahí su poder curativo (Gumpert 1988: 71 ss.). 
artículo homónimo publicado en El pobrecito hablador el 14 de enero de 1833. Como vemos, en ambos ejemplos su propósito es el de destacar la ineptitud del grupo gobernante en varios frentes: en 27, al tomar como modo de resolución de conflictos la aplicación de leyes que fracasan, y el ejemplo 28 es particularmente significativo, pues pertenece a su última réplica. Para entonces, dada la extrema gravedad que la crisis económica y financiera iniciada en 2008 había adquirido para entonces, que él achaca a la mala gestión del Gobierno socialista, instado por la proximidad de la siguiente convocatoria electoral no pierde la oportunidad para derrocar a Rodríguez Zapatero de su puesto mediante su asociación con «la nueva versión del vuelva usted mañana aplicada a los engorros»:

(27) Esta ley tuvo un apoyo unánime en esta Cámara, pero ha fracasado en su desarrollo y en su puesta en práctica, que es la tarea que corresponde al Gobierno de España. Ya advertí en su momento que este gravísimo problema no se arregla solo con leyes, señor Rodríguez Zapatero, pero ustedes se empeñaron, por propaganda, en presentarla como un bálsamo que todo lo cura (Rajoy 2007)

(28) Es la nueva versión del «vuelva usted mañana» aplicada a los engorros y a las dificultades (Rajoy 2011)

\subsubsection{Bíblicas}

Muy oportuna resulta esta alusión de origen neotestamentario y contenida en los cuatro evangelios canónicos. De esta imagen se vale el líder conservador para mostrar no solo la tozudez del Presidente ante la falta de atención prestada a las advertencias del opositor, sino también la falta de correspondencia de lo afirmado por aquel y las medidas ejecutadas posteriormente. El resultado de este doble ataque es la intensificación del perjuicio de su figura:

(29) Le dije hace un año [...] que su desmadrado gasto público provocaría un déficit $[\ldots]$ que implicaría una reducción de los créditos a las familias y a las empresas [...]. Me contestó [...] «para salir de la recesión es necesario un impulso fiscal y no hacer demagogia de si se gasta más o se gasta menos» [...]. Le dije también que era preciso abordar ya la reforma laboral [...]. Me contestó - cito textualmente-: «... si hay alguna propuesta de abaratar el despido o de recortar derechos de los trabajadores le digo que no va a pasar...». Como yo insistí, el señor Rodríguez Zapatero lo repitió en la réplica [...]. Y no satisfecho, negó evangélicamente por tercera vez (Rajoy 2010) 


\subsubsection{Históricas}

Una de las inmediatas consecuencias que achaca Rajoy al nuevo gobierno del socialista es la generación de un movimiento independentista entre sus comunidades autónomas y la consiguiente división de opiniones. La referencia a nuestro último conflicto bélico nacional es muy clara:

(30) En España vuelve a haber buenos y malos y ha resucitado el cantonalismo $^{6}$ (Rajoy 2005)

\subsection{Analogías}

Habida cuenta la efectividad de este mecanismo de cortesía relativa ${ }^{7}$ por cuanto responde a una manifiesta intención del orador por facilitar la comprensión del mensaje contenido en sus palabras, no es extraño que el portavoz de la oposición se valga del mismo en seis ocasiones. En algunas de ellas plantea un conflicto de gravedad variable (incendio en 33, guitarra desafinada en 34 y hemorragia en enfermo en 35) junto con su lógica resolución, que contrasta con las medidas tomadas en determinadas situaciones por Rodríguez Zapatero. La asociación analógica contenida en 36, por otra parte, establece la conveniencia de basar los juicios sobre el valor de un profesional (arquitecto en este caso) en el valor de sus acciones, mientras que las muestras recogidas en 31 y 32 contienen un elevado matiz

${ }^{6}$ El cantonalismo fue un movimiento insurreccional de carácter radical cuyo objetivo fue el establecimiento de una serie de ciudades o confederaciones de ciudades (cantones) independientes federadas libremente. En España hubo dos momentos históricos en los que se puede hablar de esta situación: durante la Primera República española (julio 1873-enero 1874) y más recientemente durante la Guerra Civil (1936-1939).

${ }^{7}$ El criterio para delimitar este tipo de (des) cortesía de la que consideramos absoluta estriba en la multifocalidad propia de este tipo de emisiones, determinada por la pluralidad de emisores a la que este se destina, que ya Fuentes Rodríguez (2013) estructuró en tres ámbitos o dimensiones: (a) Grupo político en el poder; en este caso, los discursos que componen nuestro corpus se constituyen como respuesta inmediata a la intervención presidencial que da inicio a los debates. (b) Representantes de los restantes grupos parlamentarios presentes en el acto. (c) Multitud de oyentes, televidentes y, en última instancia, lectores que acceden a estas comunicaciones mediante el uso de los medios de comunicación. Toda la fuerza discursiva se concentra en este último colectivo por su rol decisivo de elegir al representante en las urnas, por lo que el político, consciente de este privilegio, enfocará todos sus esfuerzos en el propósito de persuadir para prolongar su estatus ejerciendo el mandato -en el caso del Gobierno- o para alcanzarlo si se halla en la oposición. Si bien la actitud dominante con respecto al primero de estos tres será descortés, hacia el último la norma será la cortesía -aunque interesada, por cuanto constituye una estrategia para lograr un bien propio-; de ahí la relatividad de este concepto. Por el contrario, hablamos de (des)cortesía absoluta cuando la multiplicidad de receptores se reduce a la unicidad y, por tanto, la intención (des)cortés es bien clara y directa. 
despectivo en tanto pretenden evidenciar la incapacidad del presidente socialista para ejercer gestión gubernativa. Es significativo el hecho de que todas ellas sean pronunciadas en los últimos debates de las legislaturas (VIII y IX), esto es, previos a la celebración de las elecciones generales de marzo de 2008 y noviembre de 2011, respectivamente.

(31) No basta estar en el Gobierno para gobernar, como no basta tener los ojos abiertos para estar despierto (Rajoy 2007)

(32) Algunos aspectos de la economía española van bien [...], pero no se debe a que usted gobierne, del mismo modo que no amanece porque el gallo cante; aunque el gallo no cante, la noche se va y, aunque ese asiento hubiera estado vacío, la economía española iría exactamente igual (Rajoy 2007)

(33) Si alguien provoca un incendio en mi vecindario, yo le ayudaré a apagarlo porque es mi obligación, pero no renunciaré a exigir responsabilidades al incendiario (Rajoy 2007)

(34) Esto es como la guitarra, señorías, o se afinan las seis cuerdas o la guitarra sigue desafinada (Rajoy 2011)

(35) Señorías, cuando un herido sangra abundantemente no es momento para graduarle la visión; o se corta la hemorragia o todo lo demás que se pretenda será inútil (Rajoy 2011)

(36) Señorías, para juzgar a un arquitecto no nos fiamos sin más de sus palabras, le juzgamos por las obras que ha realizado (Rajoy 2011)

\subsection{Coloquialismos}

A pesar de la escasez de este recurso en el total de las seis intervenciones de Rajoy, constituyen un valioso medio para aumentar la eficacia de los ataques verbales dirigidos al Presidente, bien para destacar una consecuencia derivada de sus errores (39), calificar los excesos aplicados al gasto público (38) o bien destacar acciones contradictorias tanto en terreno económico (37) como político (40):

a) Guantazo

(37) Y sus amigos ya le han dado el primer guantazo en la negociación de los fondos de cohesión (Rajoy 2005)

b) Desmadrado

(38) Le dije hace un año, una vez más, que su desmadrado gasto público provocaría un déficit que rondaría en 10 por ciento... (Rajoy 2010) 
c) Racanear

(39) [...] ha destruido un consenso nacional, un acuerdo tranquilizador que aportaba confianza a los trabajadores y a los pensionistas [...] y se lo carga de un plumazo para racanear 1500 millones de euros... (Rajoy 2010)

d) Ningunear

(40) Después ninguneó a su partido en Cataluña llegando a acuerdos con sus adversarios políticos, a los que después también engañó (Rajoy 2010)

TABLA 5. Recuento total de particularidades léxico-retóricas

\begin{tabular}{c|c|c|c|c|c|c}
\hline \multicolumn{2}{c|}{ UNIDADES FRASEOLÓGICAS } & \multicolumn{3}{c|}{ REFERENCIAS } & \multirow{2}{*}{ ANALOGÍAS } & COLOQUIALISMOS \\
\cline { 1 - 4 } Locuciones & $\begin{array}{c}\text { Enunciados } \\
\text { fraseológicos }\end{array}$ & Literarias & Bíblicas & Históricas & & \\
\hline 26 & 6 & 2 & 1 & 1 & 6 & 4 \\
\hline \multicolumn{2}{c|c}{ TOTAL $=32$} & \multicolumn{3}{c|}{ TOTAL $=4$} & TOTAL $=6$ & TOTAL $=4$ \\
\hline
\end{tabular}

\section{Conclusiones}

Como hemos visto en nuestro análisis, sobre todos los elementos estudiados en las réplicas de Mariano Rajoy destacan las unidades fraseológicas, y dentro de ellas las locuciones, emitidas con dos propósitos fundamentales: atacar al interlocutor y reforzar la autoimagen positiva. Sin embargo, habida cuenta del papel deslegitimador ejercido desde la oposición y la consiguiente búsqueda de estrategias que invaliden la imagen positiva del adversario, son las de ataque las que alcanzan un lugar protagónico sobre las segundas.

En otra instancia, las paremias y analogías se encuentran en una proporción similar, un total de seis unidades totales en nuestro corpus, a las que siguen las referencias y coloquialismos igualmente en la misma cuantía con una diferencia de dos con respecto a las anteriores.

De todo lo anterior se deduce la elección de las locuciones sobre las demás unidades, consideradas por el portavoz de la oposición como valioso medio para aumentar la eficacia discursiva de sus comunicaciones no solo por su riqueza expresiva sino también por su capacidad de impacto en los destinatarios, esto es, los electores. 


\section{BIBLIOGRAFÍA}

CASARES SÁNCHEZ, Julio (1950): Introducción a la lexicografía moderna, Madrid: CSIC. Corpas PAStor, Gloria (1997): Manual de fraseología española, Madrid: Gredos.

Fuentes RodRíGuez, Catalina (2013): «Argumentación, (des)cortesía y género en el discurso parlamentario», Tonos, Revista digital 25, 1-26.

Gumpert, C. (1988): «La historia del emperador Carlomagno como fuente de Cervantes», Dicenda, Cuadernos de Filología Hispánica 7, 73-81.

Martí SÁnCHEZ, Manuel (1999): «Problemas e implicaciones teóricas en el estudio de $n i »$. En Jesús Fernández González et alii (eds.), Lingüistica para el siglo XXI, vol. II, Salamanca: Universidad de Salamanca, 1095-1100.

Real Academia Española (2001): Diccionario de la lengua española. <http://www. rae.es>.

Ruiz GuRILLO, Leonor (1997): Aspectos de fraseología teórica española, Valencia: Universitat de València.

- (2000): «La fraseología». En Antonio Briz y Grupo Val.Es.Co. (coords.), ¿Cómo se comenta un texto coloquial?, Barcelona: Ariel, 169-189.

Sevilla MuÑoz, Julia y Álvaro Arroyo Ortega (1993): «La noción de 'expresión idiomática' en francés y en español», RFFr 4, 247-261.

Zuluaga OsPINA, Alberto (1980): Introducción al estudio de las expresiones fijas, Tübingen: Max Hueber Verlag. 